\title{
Notes on the vocalizations of Slaty Thrush (Turdus nigriceps)
}

Peter Boesman

In the following we briefly analyze and compare voice of the two races of Slaty Thrush (Turdus nigriceps). We also try to quantify the extent of any vocal differences using the criteria proposed by Tobias et al. (2010), as a support for taxonomic review.

We have made use of sound recordings available on-line from Xeno Canto (XC).

nigriceps

Song typically starts with some jumbled medium-pitched whistles and gradually shifts towards high-pitched 'see' notes. Phrase length typically c. 4s or longer.

Some examples:

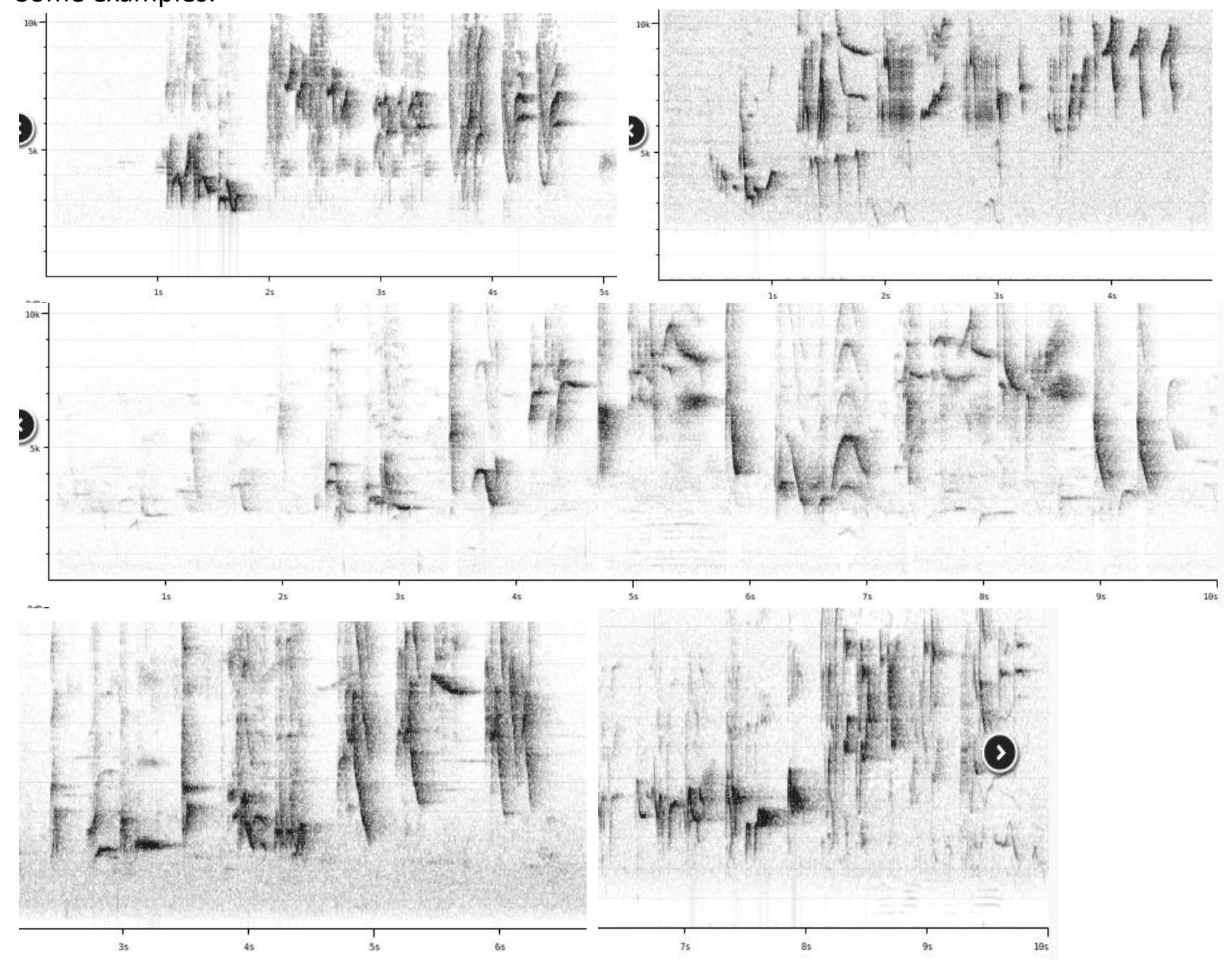



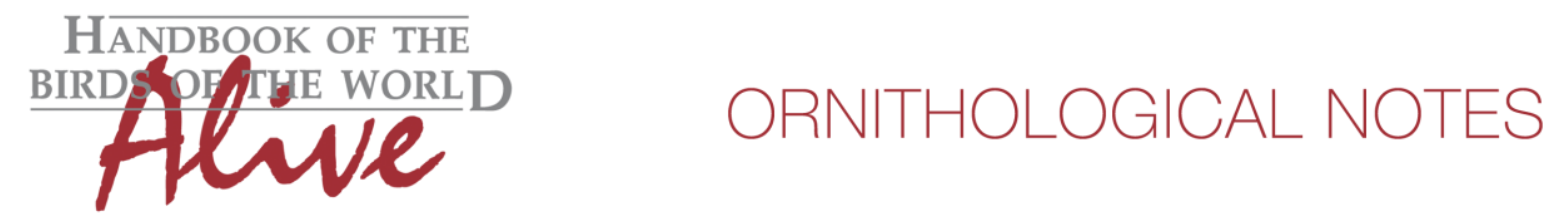

\section{subalaris}

Song is a repetition of some 4-5 similar-sounding dissonant notes (occasionally more), often preceded by a high-pitched descending whistle. Phrase length typically c. 1.5s (excluding the intro whistle).

Some examples:

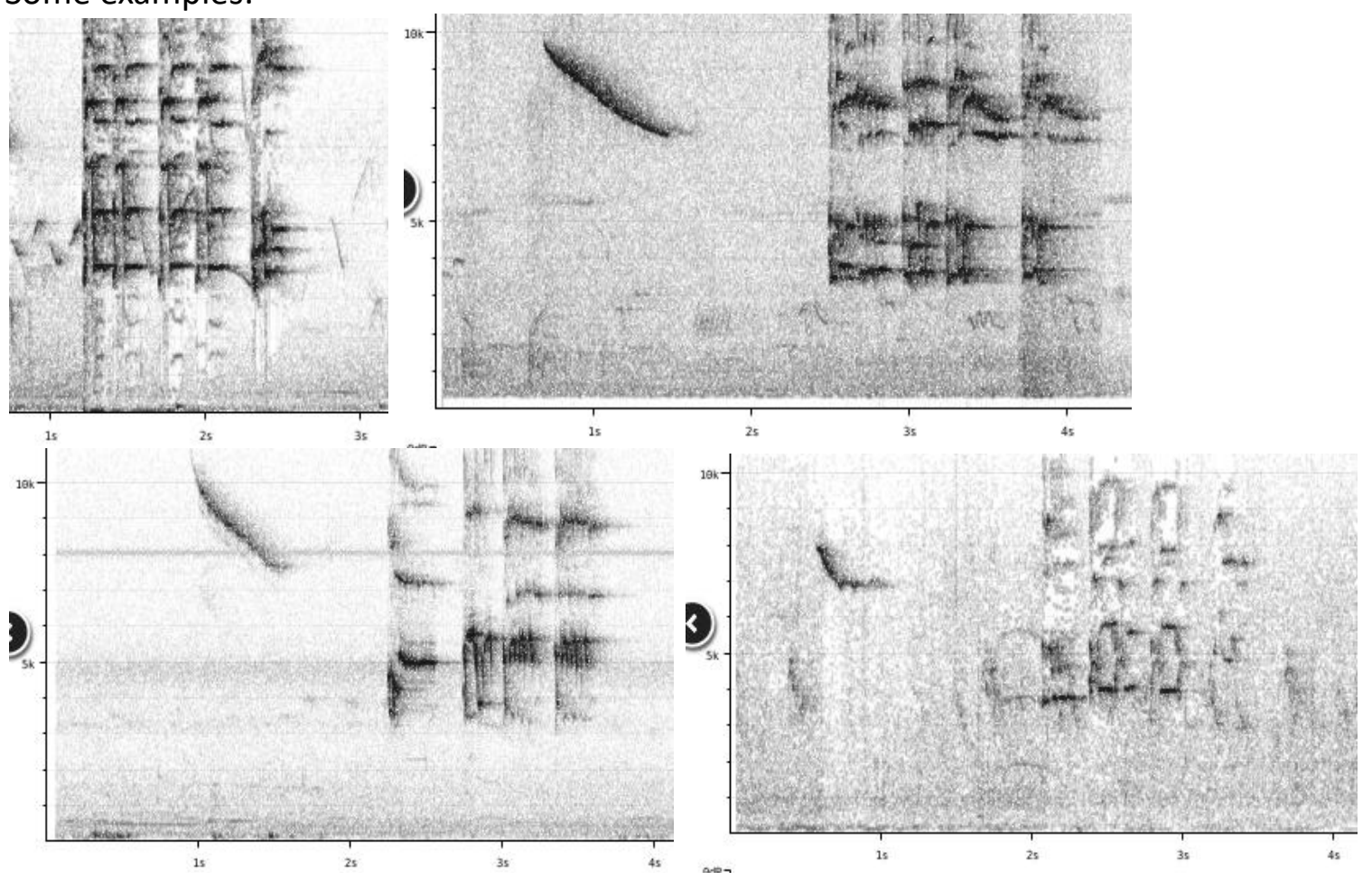

From the above, it is clear that song of both taxa is VERY different.

Vocal difference could be quantified and scored as follows:

nigriceps has a longer song phrase (score 3) with more and different notes (score 3) and has a clear difference in average pitch between start and finish (score 2). When applying Tobias criteria, this would lead to a total vocal score of about 6 .

This note was finalized on 20th April 2016, using sound recordings available on-line at that moment. We would like to thank in particular the many sound recordists who placed their recordings for this species complex on XC.

\section{References}

Tobias, J.A., Seddon, N., Spottiswoode, C.N., Pilgrim, J.D., Fishpool, L.D.C. \& Collar, N.J. (2010). Quantitative criteria for species delimitation. Ibis 152(4): 724-746.

\section{Recommended citation}

Boesman, P. (2016). Notes on the vocalizations of Slaty Thrush (Turdus nigriceps). HBW Alive Ornithological Note 308. In: Handbook of the Birds of the World Alive. Lynx Edicions, Barcelona. (retrieved from http://www.hbw.com/node/1251765 on 15 October 2016). 